\title{
Inhibition of vasopressin secretion during migraine
}

\author{
C J M POOLE, S L LIGHTMAN \\ From the Medical Unit, Westminster Hospital, London UK
}

SUMMARY Six subjects with a history of increased urinary frequency during migraine were studied. In each case there was a marked diuresis and natriuresis within 12 hours of onset of the headache. This was associated with a significant fall in urinary arginine vasopressin (AVP) $(p<0.01)$. Migraine may be associated with altered hypothalamic activity resulting in reduced AVP secretion.

The passing of copious volumes of dilute urine during migraine was noted as long ago as 1873 by Liveing ${ }^{1}$ and in a recent study $24 \%$ of migraineurs reported either a change in urinary frequency or symptoms suggestive of fluid retention during their migraines. ${ }^{2}$ Increased urinary frequency is the most common symptom although oliguria, weight gain, increased girth and tightness of rings may be experienced. Schottstaedt and Wolff ${ }^{3}$ reported decreased water and sodium clearance during the early phase of migraine, followed by increased water and sodium clearance during the recovery phase. However, attemps to modify the headache by inducing a diuresis during the early part of the migraine were unsuccessful. Similar observations had been made by Cambell et $\mathrm{al}^{4}$ who postulated alterations in the secretion of vasopressin (AVP) and aldosterone during migraine. We have now studied changes in vasopressin secretion during spontaneous episodes of migraine in six migraineurs.

\section{Subjects and methods}

Subjects were recruited from outpatient clinics at the National Hospital for Nervous Diseases or the Princess Margaret Migraine Clinic, Charing Cross Hospital, London. A history of migraine was determined using previously defined criteria. ${ }^{5}$ Those who had noticed a change in urinary frequency during their migraines were invited to participate in the study. Subjects were asked not to take any medication either prophylactically or acutely for the period of the study.

As soon as the migraineur became aware of the start of a

Address for reprint requests: Dr C J M Poole, Hunters Rise, Holy Cross Green, Clent, Worcs DV9 0HG.

Received 29 April 1988 and in revised form 18 July 1988. Accepted 21 July 1988 migraine the subject voided, discarding the urine. Voiding then took place at two-hourly intervals, for a total of 12 hours, recording the volume of urine passed in a measuring beaker and pouring approximately $20 \mathrm{ml}$ into a screw-topped labelled specimen bottle. Fluid input was also recorded during the migraine; one cup was taken as $150 \mathrm{ml}$ for the purposes of this study. Specimen urine bottles were kept in a refrigerator at $4^{\circ} \mathrm{C}$ until the next morning when they were either collected or sent by Red Star post to a London mainline station where they were met on arrival.

Urine osmolality (Osmomat 030, Gonotec, Berlin), and sodium concentrations (flame photometer) were measured in unfrozen aliquots and the rest of the samples stored at $-20^{\circ} \mathrm{C}$ for subsequent assay of AVP and oxytocin (OT). Control urine was obtained in a similar manner from the same six migraineurs during a headache-free day at least 3 days after their last migraine. Urine from 6 non-migrainous subjects acted as an additional control.

In one subject both plasma and urine were obtained simultaneously during a spontaneous attack of common migraine. In this case the first blood sample was taken 45 minutes after the subject first became aware of the onset of the migraine and then at 30 minute intervals for 4 hours. Ten $\mathrm{ml}$ aliquots of blood were collected into heparinised tubes, centrifuged at $1,500 \mathrm{~g}$ for 10 minutes in a portable centrifuge, separated and the plasma divided into two aliquots. One was transported in a plastic storage tube at ambient temperature for measurement of sodium and osmolality; the other was transported in a plastic storage tube in dry ice and stored at $-20^{\circ} \mathrm{C}$ for subsequent assay of AVP, OT and alpha human atrial natriuretic peptide (ANP). Urine was collected 2hourly and a careful record of fluid input charted as above for 12 hours. A convalescent blood sample was taken 3 days after the end of the migraine.

Fractions of urine and plasma were assayed for AVP and OT by direct radioimmunoassay as previously described. ${ }^{67}$ Fractions of plasma were assayed for ANP as described.8 Results were expressed as mean, SEM. The Student's $t$ test and Wilcoxon matched pairs test were used where 
appropriate; $p>0.05$ was taken to be not significant (NS).

Urinary AVP and OT excretion rate were expressed as pmol/

2 hours and urine volumes as $\mathrm{ml} / 2$ hours.
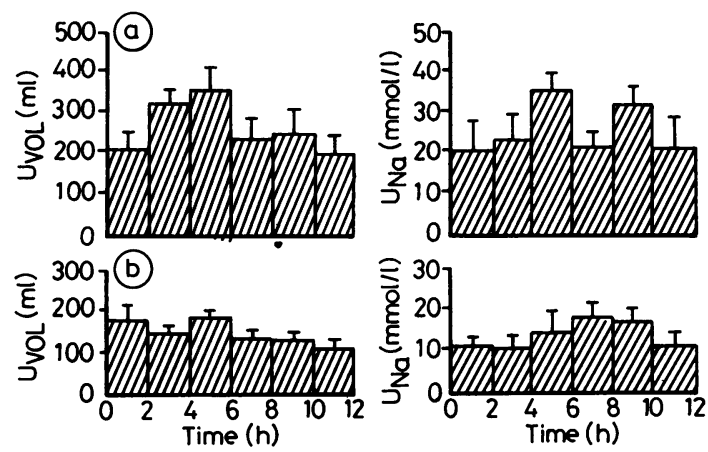

Fig 1 Urine volume ( $U$ vol) and urinary sodium ( $U \mathrm{Na}$ ) at 2 hourly intervals in migraineurs during (a) spontaneous migraine and $(b)$ control period at least 72 hours from the last migraine. Mean, SEM. $n=6$ for both $(a)$ and $(b)$.

\section{Results}

All migraineurs studied were female, mean age 36 years (range 28 to 49); three had classic and three common migraine. One migraineur was premenstrual when studied and another was taking a combined oral

Table Plasma changes during an episode of spontaneous migraine

\begin{tabular}{|c|c|c|c|c|c|}
\hline \multirow[b]{2}{*}{ Time } & \multicolumn{5}{|l|}{ Plasma } \\
\hline & $\begin{array}{l}\mathrm{Na}+ \\
(\mathrm{mmol} / \mathrm{l})\end{array}$ & $\begin{array}{l}\text { Osmolality } \\
\text { (mosmol/kg) }\end{array}$ & $\begin{array}{l}A V P \\
(\mathrm{pmol} / \mathrm{l})\end{array}$ & $\begin{array}{l}O T \\
(p m o l / l)\end{array}$ & $\begin{array}{l}\text { ANP } \\
(\mathrm{pmol} / \mathrm{l})\end{array}$ \\
\hline $\begin{array}{l}13 \cdot 00 \\
30 \\
14 \cdot 00 \\
30 \\
15 \cdot 00 \\
30 \\
16.00 \\
30 \\
\text { Convalescent }\end{array}$ & $\begin{array}{l}131 \\
135 \\
144 \\
153 \\
150 \\
147 \\
137 \\
138 \\
141\end{array}$ & $\begin{array}{l}284 \\
298 \\
303 \\
303 \\
296 \\
285 \\
285 \\
288 \\
291\end{array}$ & $\begin{array}{l}0.75 \\
1.19 \\
0.99 \\
1.19 \\
1.66 \\
1.77 \\
1.06 \\
1.11 \\
2.30\end{array}$ & $\begin{array}{l}3 \cdot 1 \\
2 \cdot 7 \\
4 \cdot 8 \\
3 \cdot 3 \\
8 \cdot 1 \\
8 \cdot 7 \\
2 \cdot 3 \\
4 \cdot 3 \\
7 \cdot 3\end{array}$ & $\begin{array}{r}72 \\
132 \\
140 \\
101 \\
96 \\
99 \\
105 \\
64 \\
57\end{array}$ \\
\hline
\end{tabular}

Fluid intake $09.00-21.00=700 \mathrm{ml}$.

Urine output $09.00-21.00=1870 \mathrm{ml}$ 
contraceptive pill. All attacks occurred during the day with headaches lasting from 7 to 12 hours. During migraine there was a marked increase in urine volume $(p<0.01)$ (fig l) and a fall in the excretion of AVP (fig 2). The mean nadir of urinary AVP excretion rate was $1 \cdot 1$, SEM $0.24 \mathrm{pmol} / 2 \mathrm{hr}$ during migraine and $2 \cdot 8$, SEM $0.45 \mathrm{pmol} / 2 \mathrm{hr}$ when migraine free $(\mathrm{p}<0.01)$. The corresponding urinary oxytocin was 1.8 , SEM 0.51 and $2 \cdot 1$, SEM $0.46 \mathrm{pmol} / 2 \mathrm{hr}$ (NS). Excretion of urinary sodium increased significantly during migraine $(p<0.001)$ (fig 1). Fluid intake and urine output during migraine were 971, SEM 162 and 1543, SEM $186 \mathrm{ml} / 12$ hours respectively $(\mathrm{p}<0.01)$. Fluid intake in migraineurs between migraines was 1050 , SEM $118 \mathrm{ml} / 12$ hours (NS compared with intake during migraine) and urine output between migraines was $910 \mathrm{ml} / 12$ hours $(\mathrm{p}<0.01$ compared with output during migraine). There was no significant difference in urine volume, urinary AVP or urinary OT between controls and migraine free migraineurs (data not shown).

In the one patient from whom we were able to obtain plasma as well as urine specimens, there was a negative fluid balance of at least one litre during the first 12 hours of the migraine (table). Plasma sodium, osmolality and ANP increased, AVP remained inappropriately low and oxytocin did not change. Heart rate and blood pressure (portable mercury sphygmomanometer) remained in the range 64-72 $\mathrm{bpm}, 100 / 60-110 / 80 \mathrm{~mm} \mathrm{Hg}$ respectively throughout.

\section{Discussion}

The finding of a diuresis and natriuresis during migraine is in keeping with previous observations. ${ }^{13} \mathrm{~A}$ negative fiuid balance of $600 \mathrm{ml}$ and in some cases greater than one litre suggests that thirst and prostration the following day may be related to the resulting changes in fluid and electolyte balance, and our data imply that the mechanism for the diuresis is inhibition of AVP secretion. Urinary AVP, and in the one subject studied plasma AVP concentrations were significantly and inappropriately reduced during migraine, while the other neurohypophyseal hormone, oxytocin, remained unchanged suggesting a selective inhibitory mechanism for AVP release. This finding is particularly remarkable as nausea or vomiting was experienced by all the migraineurs and is normally a potent stimulus for AVP secretion.'

Opiates, dopamine ${ }^{10}$ and ANP" may have inhibitory effects on AVP release. Opiates may be released centrally during pain and inhibition of AVP secretion could be secondary to non-specific activation of endogenous opioid peptides during migraine. This would be amenable to experimental assessment using an opiate antagonist such as naloxone.
It is of interest that in one patient who prior to inclusion in the study took a dopamine antagonist (domperidone) as treatment for her migraine noticed a reduction in urine volumes during those attacks in which she took domperidone. This was not confirmed objectively but suggests a possible role for dopamine as an inhibitor of AVP release during migraine. Atrial natriuretic peptide may also inhibit the release of AVP as well as cause a natriuresis and is therefore another candidate for a role in migraine associated diuresis and natriuresis. It is of note that in the one patient from whom plasma was obtained, concentrations of ANP reached 130-140 pmol/1, which are within the range of ANP associated with diuresis and natriuresis. ${ }^{12}$ Unfortunately it was not possible to obtain plasma samples during further spontaneous migraines, but if this anecdotal observation could be repeated it would suggest activation of a cerebro-cardiac mechanism since the concentrations of ANP in the brain are very low.

The changes in AVP secretion suggest that a modification of hypothalamic activity occurs during migraine and would be compatible with the idea of spreading electrical depression, described by $\mathrm{LeaO}^{13}$ in the pathogenesis of migraine. This may involve local changes in electrical activity and neurotransmitter release resulting in inhibition of firing of cells in the hypothalamic supraoptic and paraventricular nuclei.

This study was approved by the Ethics Committee at Westminster Hospital.

\section{References}

1 Liveing E. On migraine, Sick headache and Some Allied Disorders: a Contribution to the Pathology of Nerve Storms. London: J and A Churchill. 1873.

2 Blau JN. Resolution of migraine attacks: sleep and the recovery phase. J Neurol Neurosurg Psychiatry 1982; 45:223-6.

3 Schottstaedt WW, Wolff HG. Variation in fluid and electrolyte excretion in association with vascular headache of the migraine type. AMA Arch Neurol Psychiatry 1955:73:158-64.

4 Cambell DA, Hay KM, Tonks EM. An investigation of the salt and water balance in migraine. $\mathrm{Br}$ Med $J$ 1951;2:1424-9.

5 Poole CJM. Migraine. Br J Hosp Med 1986;Aug:90-3.

6 Williams TDM, Carter DA, Lightman SL. Sexual dimorphism in the posterior pituitary response to stress in the rat. Endocrinol 1985;116:738-4.

7 Robinson ICAF. The development and evaluation of a sensitive and specific radioimmunoassay for oxytocin in unextracted plasma. J Immunoassay 1980;1:323-47.

8 Walsh KP, Williams TDM, Canepa-Anson R, Pitts E, Lightman SL, Sutton R. Effects of endogenous natriuretic peptide released by rapid atrial pacing in dogs. Am J Physiol 1987;253:R599-R604.

9 Robertson GL. The regulation of vasopressin function in 
health and disease. Recent Prog Horm Res 1977;33: 380-5.

10 Carter DA, Lightman SL. Neuroendocrine control of vasopressin secretion. In: Baylis PH, Padfield eds. The Posterior Pituitary. New York: Marcel Dekker 1985: 53-118.

11 Poole CJM, Carter DA, Vallejo M, Lightman SL. Atrial natriuretic factor inhibits the stimulated in vivo and in vitro release of vasopressin and oxytocin in the rat. $J$ Endocrinol 1977;112:97-102.

12 Anderson JV, Donckier J, Payne NN, Beacham J, Slater JD, Bloom SR. Atrial natriuretic peptide: evidence of action as natriuretic hormone at physiological plasma concentrations in man. Clin Sci 1987;72:305-12.

13 Leao AAP. Spreading depression of activity in cerebral cortex. J Neurophysiol. 1944;7:359-90. 